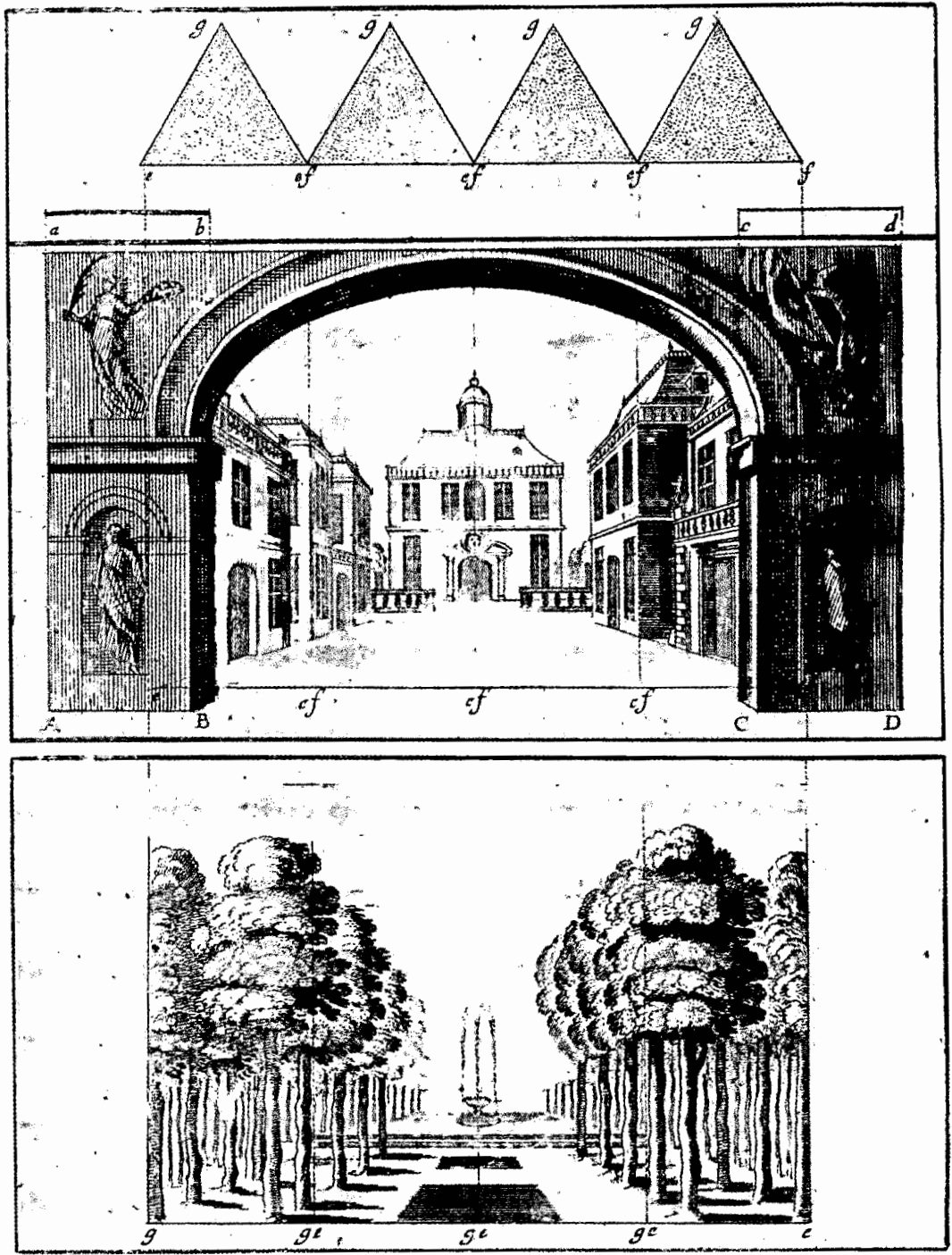




\section{Pedro Salmerón Sanginés / Pablo Serrano Alvarez}

Pedro Salmerón Sanginés es licenciado, maestro y candidato a doctor en Historia por la Facultad de Filosofía y Letras de la UNAM. Ha publicado un libro y varios artículos académicos sobre diversos temas de la historia política y la historiografía del siglo xx mexicano. Es profesor de asignatura en la Facultad de Filosofía y Letras de la UNAM y representante de los estudiantes de doctorado en el Comiré Académico del posgrado en Historia de la misma universidad. Actualmente es subdirector de Evaluación Histórica del INEHrM, donde coordina el seminario de Historia Política del Siglo XX Mexicano: los Presidenciables Frustrados, 1920-1970.

Pablo Serrano Álvarez es licenciado en Historia por la UAM; maestro en Estudios Regionales por el Instituto Mora y doctor en Historia por la UNAM. Ha sido investigador de tiempo completo en la Universidad de Colima y el Insticuto de Investigaciones Históricas de la UNAM, actualmente es director de investigación del INEHRM, e investigador nacional nivel II del Sistema Nacional de Investigadores. Es miembro de numerosas asociaciones académicas y profesionales; ha impartido 48 cursos y seminarios en distintas universidades del país y del extranjero. Especializado en la historia regional de México entre los siglos XIX y Xx ha publicado sobre diversos temas: movimientos sociales regionales, procesos electorales, historia económica de empresas y empresarios, extranjeros y migración, biografía, historia diplomática, historia contemporánea de México, historia política y metodología de la investigación histórica regionalista. Dichas publicaciones han aparecido en México, España, Argentina, Brasil, Cuba, Alemania y Estados Unidos, tanto en revistas especializadas como en editoriales de carácter académico.

\section{Resumen}

El presente artículo hace un balance de la historiografía política de tema regional sobre México, publicada a partir de 1968, partiendo de un análisis del contexto nacional, historiográfico y político, que permite o precipita el auge de esta historiografía, así como del revisionismo histórico de la revolución mexicana con el que la historiografía regionalista está íntimamente vinculada; este contexto lo determinan la "revolución del 68" y sus secuelas. La segunda parte del artículo la constituye el balance propiamente dicho, que pone énfasis en los impulsos, los logros y las carencias de la historiografía regional y, principalmente, en su pertinencia, que últimamente ha sido puesto en duda por varios analistas.

Palabras clave:

México, historiografía, siglo xx, nación-región, revisionismo.

\section{Abstract}

This article assesses the political historiography of regional issues in Mexico, published from 1968 onwards, beginning with an analysis of the national, historiographic and political context that permitted or precipitated the rise of this historiography, and the historical revisionism of the Mexican Revolution, to which regional historiography is closely linked. This context is determined by the " 68 Revolution" and its consequences. The second part of the article consists of the evaluation itself, which highlights the impulses, achievements and shortcomings of regional historiography, and above all, its relevance, recently questioned by various analysts.

Key words:

Mexico, historiography, $20^{\text {th }}$ century, nationregion, revisionism.

Fecha de recepción:

septiembre de 2002

Fecha de aceptación:

diciembre de 2002 


\title{
El auge de la historiografía política regionalista en México, 1968-2000. Revisionismo y análisis político*
}

\author{
Pedro Salmerón Sanginés \\ Pablo Serrano Álvarez
}

\section{EL CONTEXTO HISTORIOGRÁFICO}

NACIONAL

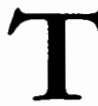

Tomamos como punto de partida una fecha simbólica (1968) porque creemos que a partir de ese año fueron ganando terreno rápidamente una serie de tendencias historiográficas que si bien existían con anterioridad, es a partir de entonces que van a convertirse en dominantes, tanto en la academia como, lo que es más significativo, en un creciente público lector. Entendemos el movimiento de 1968 como una revolución, tal como la explica Immanuel Wallerstein, como "una revolución peculiar" que cambió definitivamente "las realidades ideológico-culturales" del "sistemamundo". 1

\footnotetext{
* Este trabajo se presentó originalmente como ponencia en el Tercer Congreso Europeo de Latinoamericanistas, celebrado en Amsterdam, Países Bajos, del 3 al 6 de julio de 2002. Sirva la ocasión para agradecer a Javier Garciadiego el apoyo brindado para que pudiéramos presentarlo entonces.

${ }^{1}$ Véase las tesis sobre la revolución de 1968, sus orígenes y sus resultados, en Wallerstein, "1968", 1998 , pp. 229-249. Wallerstein entiende por "sistema-mundo" al "moderno sistema mundial, que es una economía-mundo capitalista", que existe desde el siglo xvi en una región del mundo, que se globalizó en el siglo xIX y llegó a todos los rincones del
}

Ahora bien, la utilidad y pertinencia del concepto de revolución ha venido complicándose, pues, como ha mostrado Luis Villoro, los historiadores "revisionistas" de las revoluciones estadunidense, francesa, rusa y mexicana han terminado por desechar "la noción de ruptura y recomienzo" como lo significativo de una revolución: vista desde un periodo largo, la ruptura con el pasado habría sido más ilusoria que real. En fin, si la continuidad prevalece sobre el cambio, si la revolución no es un giro decisivo, si tiene lugar más en la mente de sus actores que en la realidad histórica ¿sigue siendo un concepto útil para la historia? ${ }^{2}$ Wallerstein sostiene también "que no ha habido revoluciones en los estados que conforman el moderno sistema mundial, y que no podía haberlas si por revolución entendemos un cambio que transforma la estructura social subyacente y el funcionamiento del Estado", aunque las llamadas revoluciones

globo en la segunda mitad del siglo xx. Una de sus características fundamentales es la creación de los Estados nacionales. En fin, "El moderno sistema mundial era, y es, un sistema capitalista, es decir, un sistema que opera sobre la premisa de la acumulación incesante de capital a través de la mercantilización de todo." Wallerstein, Utopística, 1998, pp. 11-12.

2 Villoro, "Sobre", 1993, p. 71. 
"han sido elementos muy importantes en la historia de la evolución del moderno sistema mundial". 3

Aunque muchos de los historiadores revisionistas de la revolución mexicana no estarían de acuerdo con él, es a partir de la cuidadosa lectura de sus obras que Villoro propone una reformulación del concepto de revolución, según el cual, lo que caracteriza a las revoluciones modernas ${ }^{4}$ no es la transformación de las estructuras, sino la de la "actitud", o la relación de los individuos y grupos con la sociedad y la manera de entenderla y de ubicarse en ella. ${ }^{5} \mathrm{Si}$ es esto lo que caracteriza a una revolución, la del 68 indudablemente lo es, y es también este cambio de actitud (aunque no lo llamen asî) lo que resulta significativo en la obra de ciertos "revisionistas" de la revolución mexicana: en la obra de Arnaldo Córdova, por ejemplo, si bien queda claro que la revolución pertenece al mismo proceso histórico iniciado

${ }^{3}$ Wallerstein, Utopistica, 1998, p. 11.

${ }^{4}$ Tómese en cuenta, incluso, que el término, aplicado a las sociedades humanas es igualmente moderno, pues se usó por primera vez para la "revolución gloriosa" de 1688, en Inglaterra. Villoro, "Sobre", 1993 , p. 69.

${ }^{5}$ Las actitudes son las "disposiciones comunes a los miembros de un grupo, favorables o desfavorables hacia la sociedad existente, que se expresan en creencias sobre la sociedad de acuerdo con preferencias y rechazos e impulsan comportamientos consistentes con ellas. Las actitudes implican la adhesión a ciertos valores y el rechazo a situaciones que no permiten realizarnos", ibid., p. 72. Como ha señalado María José Garrido, esta definición acusa una clara influencia del pensamiento de Ortega y Gasset, en particular en la forma en que éste define las ideas y las creencias y el lugar de ambas en la conformación de una ideología. Garrido, "Caminos"; apud. Ortega y Gasset, "Ideas", 1943, t. II, pp. 1657-1700. en México con el triunfo de la república (si no es que antes), acelerado por la revolución, y que puede resumirse en una frase: el desarrollo del capitalismo en México, también es cierto que "la revolución fue una gigantesca movilización de masas", que llevaron su programa, sus exigencias y su influencia al primer plano de la vida nacional. ${ }^{6}$ Los revisionistas franceses lo explican de manera más simple: no es que la revolución haya transformado radicalmente las estructuras de Francia, pero sí convirtió a los súbditos en ciudadanos, sí transformó la actitud del grueso de la sociedad francesa, aunque antes de esto ya hubiese quienes proclamaban, exigían o soñaban tal cambio. ${ }^{7}$

La revolución de 1968, que lo fue en el sentido anteriormente señalado, tuvo sus epicentros en Francia, Estados Unidos, Checoslovaquia, México e Italia, pero sus alcances y repercusiones fueron mundiales. ${ }^{8}$ Se cuestionó decididamente la hegemonía estadunidense en el mundo occidental y el aval soviético de esta hegemonía a cambio del respeto de su dominio sobre los países del "socialismo

\footnotetext{
${ }^{6}$ Véase sobre todo las dos obras más leídas de este autor, Córdova, Ideología, 1973, y Política, 1974.

${ }^{7}$ Véase, por ejemplo, Furet, Pensar, 1980. Véase también un excelente análisis particular de la distancia entre lo soñado por los revolucionarios y la realidad de la revolución en Deutscher, Trotsky, 1968, t. II, pp. 16-79.

${ }^{8}$ Para evitar confusiones, es importante señalar que la revolución del 68 y sus efectos no se restringen, evidentemente, a los 100 días de euforia de un movimiento estudiantil restringido a la capital de la república y reprimido a sangre y fuego, sino a una revolución en la idea del mundo de los jóvenes de esa generación, que no necesariamente es resultado de los hechos que sacudieron la ciudad de México entre el 26 de julio y el 2 de octubre de aquel año.
} 
real"; 9 y se cuestionó con mayor fuerza todavía la homogeneidad de la cultura (en la más amplia acepción de la palabra) del mundo occidental, y_de paso, la de los Estados-nación, en cuyo seno empezaron a reivindicarse lenguas, tradiciones e historias diferentes.

La historiografía resultante de la revolución de 1968 fue en busca de esas diferencias hasta entonces acalladas por los intentos homogeneizadores de lo "occidental" en primer lugar, y de lo "nacional" en segundo, esas diferencias existentes, subterráneas, violentas a veces. Lo primero fue el tránsito de la historia global (las historias "universales" centradas en occidente, y las historias "nacionales" enseñadas en las escuelas) a las historias regionales (o de "nacionalidades", en los estados en que éstas habían sido sometidas a lo nacional en singular); luego fueron la microhistoria, la búsqueda de lo subterráneo, la vida cotidiana, el género. ${ }^{10}$

Estas tendencias generales tuvieron una vida distinta en cada país. En México, el combate a la hegemonía estadunidense y a una cultura y una moral monolíticas, se tradujeron en la crítica frontal al sistema político que asumía esas premisas y las sazonaba con un autoritarismo peculiar, ${ }^{11} \mathrm{y}$ cuyas modalidades autoritarias y

\footnotetext{
9 Hegemonía que, por otro lado, empezaba a tambalearse, como muestra Wallerstein, "1968", 1998 , pp. $230-232$.

${ }_{10}$ Torres, Revolución, 2001, pp. 113-115. Apud. Giovanni Levi y Carlo Ginzburg.

11 Sobre la "peculiarísima peculiaridad" (parafraseando a Jesús Silva Herzog) del sistema político mexicano, puede verse cómo Giovanni Sartori tuvo que crear una categoría en la que únicamente encajaba el sistema político mexicano: Sartori, Partidos, 2000 , pp. 275-287.
}

represivas (lo mismo que su agotamiento como sistema político y la crisis del modelo de desarrollo económico que había adoptado) fueron sacadas a plena luz por la revolución del $68 .{ }^{12}$ Lo segundo, la búsqueda de lo distinto, de lo subterráneo, de las diferencias hasta entonces escondidas, apareció en forma de una vigorosa historiografía regional.

La primera de estas tendencias, el "revisionismo histórico de la revolución mexicana", arrancó entre 1967 y $1973,{ }^{13}$ con la publicación de los libros de John Womack, Arnaldo Córdova, Adolfo Gilly, Jean Meyer, Lorenzo Meyer y James D. Cockroft; la segunda es simultánea, si consideramos que Womack y Cockroft son los primeros revisionistas que parten del estudio de una región particular. Luego vendrían muchas otras revisiones globales del proceso revolucionario, destacadamente las de Friedrich Katz, François Xavier Guerra, Ramón Eduardo Ruiz, John M. Hart y Alan Knight; y aun más historias regionales de las que hablaremos después.

Esta historia fue escrita por historiadores nacidos después de 1935 (salvo excep-

${ }^{12}$ Salmerón, "Pensar", 2000, p. 111.

${ }^{13}$ Álvaro Matute ha señalado correctamente que muchas de estas investigaciones estaban terminadas o en curso cuando el 68 irrumpió, pero si entendemos que lo que el 68 sacó a la luz tenía mucho que ver con lo que estos hombres se preguntaban, y que con la excepción de Gilly todos pertenecen a la generación del 68 , podemos decir que es cierto que esta historiografía no es resultante del 68 ni fruto de esa revolución, pero sí responde -aquí es donde dejamos a Matute- a inquietudes muy parecidas a las que dieron vida a ese movimiento (y que Wallerstein explica en el ensayo que hemos citado). Véase Matute, “Actores", 1989, pp. 10-17; y "El 68", 1997, pp. 87-95. 
ciones, como Gilly y Katz), quienes se autodefinieron como pertenecientes a la "generación del 68". ${ }^{14}$ Como tales, no estaban dispuestos, como sus antecesores, a ser compañeros de viaje del Estado mexicano, ni a suscribir el paradigma de la revolución popular, agraria, nacionalista y antiimperialista que daba sustento a dicho Estado. Había que repensar el pasado. La idea del agotamiento de la revolución mexicana había sido puesta sobre la mesa por uno de los más lúcidos intelectuales mexicanos: Daniel Cosío Villegas, quien preguntó " ¿Ha muerto la revolución mexicana?" Desde la generación sesentaiochera, Rolando Cordera pidió: "El que haya encontrado a la revolución mexicana, favor de devolverla." 15

Los nuevos historiadores de la revolución, llamados genéricamente revisionistas, se empezaron a preguntar cosas que antes habían sido soslayadas: ¿quiénes hicieron la revolución?, ¿de dónde venían?, ¿qué los llevó a la revolución y qué hicieron en ella? Las preguntas empezaron a dejar de ser qué, cuándo, dónde, cómo, para dar lugar a los por qué y los para qué. La revolución dejó de ser asunto de caudillos y prohombres, para empezar a ser acción social, colectiva, y de paso perdió su carácter unitario y nacional: de aquel movimiento unívoco y comprensible, los revisionistas fueron extrayendo

14 Las "generaciones" como categoría de análisis para estudiar a las elites (en este caso, a las elites intelectuales) fue propuesta por Ortega y Gasset, Tema, 1938, pp. 11-19. Siguiendo a Ortega y Gasset, Luis González ha clasificado las generaciones de historiadores mexicanos del siglo $\mathrm{xx}$, haciendo de los nacidos entre 1935 y 1950 "la generación del 68". González, "75 años", 1988, t. IV, pp. 649-704.

is Salmerón, "Pensar", 2000. otro, múltiple y complejo, fragmentado casi hasta la inasibilidad. ${ }^{16}$

\section{LO REGIONAL Y LO POLÍTICO}

Esta búsqueda general del significado de la revolución mexicana, este intento por desmontar el discurso oficial que hacía de la revolución el sustento histórico del Estado mexicano, encontró rápidamente en la historiografía regional (de tema contemporáneo) su expresión más rica y abundante. La historiografía regional nació al mismo tiempo que el revisionismo (con Womack y Cockroft), pero fue en la segunda mitad de la década de los setenta cuando se volvió abrumadora. ${ }^{17}$

El revisionismo que implicó el estudio y el análisis de la revolución mexicana conllevó, indiscutiblemente, a la necesidad por entender y explicar el origen, el desarrollo y las consecuencias de la transformación social y política que México había experimentado con una revolución heterogénea, compleja, popular, nacionalista y transformadora de estructuras. Ante las interpretaciones lineales, homogéneas y estáticas, se impuso el interés por encontrar los vericuetos y recovecos de un proceso histórico que había transformado y cambiado a la vida política y

${ }^{16}$ Los estudios sobre el revisionismo superan con creces los trabajos sobre la historiografía anterior, vale mencionar a Florescano, Nuevo, 1991, pp. 119152; Matute, "Actores", 1989; Córdova, "Vieja", 1989; Knight, "Interpretaciones", 1990; Vanderwood, "Explicando", 1989, y Falcón, "Regiones", 1990.

1.7 Véase Falcón, "Regiones", 1990, pp. 61 y ss.; Véase también Serrano, "Historiografía", 2000, pp. 16-26; y el análisis de Medina, "Historia", 1998, pp. 293-311. 
social mexicana, pero también a los ámbitos económicos, culturales y legales. ${ }^{18}$

El revisionismo sentó sus reales dentro de la historiografía regionalista para entender la revolución como un proceso disímil, para nada monolítico, que se había expresado en grandes fragmentos, hechos, fenómenos y cambios. El escenario revolucionario había sido, al final de cuentas, un conjunto de revoluciones populares, sociales, elitistas y de grupos, cuya expresión no se había estudiado o abordado en su totalidad o especificidad por la historiografía descriptiva, positivista o historicista, mucho menos por la testimonial o militante, $o$ aquella que la sintetizaba como una totalidad estática o como fundamento abstracto que era utilizado por la historia oficial. ${ }^{19}$

Revisar la revolución como proceso histórico implicó un cambio importante dentro de la historiografía regionalista mexicana, frente a una historiografía marcada por el oficialismo, la ideología, la historia de bronce o el academicismo pseudomarxista of funcionalista. ${ }^{20}$

La evolución del Estado mexicano posrevolucionario había constatado que su fundamento de legitimidad y cohesión, la revolución, se había constituido a partir de bases ideológicas, interpretaciones nacionalistas y valores identitarios o características sociales, que iban en contra de la realidad, pero también a partir de susten-

\footnotetext{
${ }^{18}$ Knight, "Interpretaciones", 1990, pp. 193 y ss.

${ }^{12}$ Véase Serrano, "Historiografía", 2000, pp. 4 y ss.; Martínez, Sentimientos, 2001, pp. 71-82; Benjamin, "Leviatan", 1985, pp. 195-217; "Revolución", 1996 , pp. 427 y ss.

${ }^{20}$ Ver los textos, en este sentido, de Bailey, "Revisionism", 1978, pp. 62-79; Carr, "Recent", 1980, pp. 3-14; Hall, “Mexican", 1987, pp. 413-420.
}

tos y proyectos sociales y políticos disímiles y heterogéneos. ${ }^{21}$

El nacionalismo revolucionario había hecho de la revolución un mito y un símbolo, un monolito homogéneo y estático $y$, por añadidura, un ente abstracto que servía a la ideología oficial y a la cohesión del fundamento del autoritarismo y el sistema político. Para estos fines, la historiografía anterior a los setenta había cumplido bien su papel dentro de la perspectiva oficialista y de la historia de bronce. ${ }^{22}$

La preocupación por los rasgos definitorios de la historia contemporánea de México, que arrancaba con la revolución, seguía con la posrevolución y fundamentaba al presente contemporáneo en mucho tuvo que ver con el autoritarismo del Estado, la democracia dictatorial, el mantenimiento de una clase política oficial que se sentía heredera y dueña de la revolución, la ideología oficialista conectada a la identidad nacional, la dictadura del partido oficial y el centralismo en todos los ámbitos de la vida mexicana. ${ }^{23}$

Desde finales de los sesenta, la historiografía de tema mexicano proveniente de la academia, comenzó a brindar signos de cambio y renovación, concentrándose en las ausencias temáticas, pero también en las carencias y en el análisis teórico-metodológico. La historiografía académica fue la impulsora indiscutible de esta renovación, conjugando la vocación multidisciplinaria con objetos de estudio innovadores, como los estudios dedicados al

${ }^{21}$ Véase las consideraciones de Loaeza, "Cambio", 1990, pp. 529 y ss.

${ }^{22}$ Pérez, "Historia", 1998, pp. 289-290.

${ }^{23}$ González, "Suave", 1983, pp. 17-22; González, "Usos", 1983, pp. 8-9. Véase también las consideraciones de Florescano, "Influencia", 1976, pp. IV-XI. 


\section{SECUENCIA}
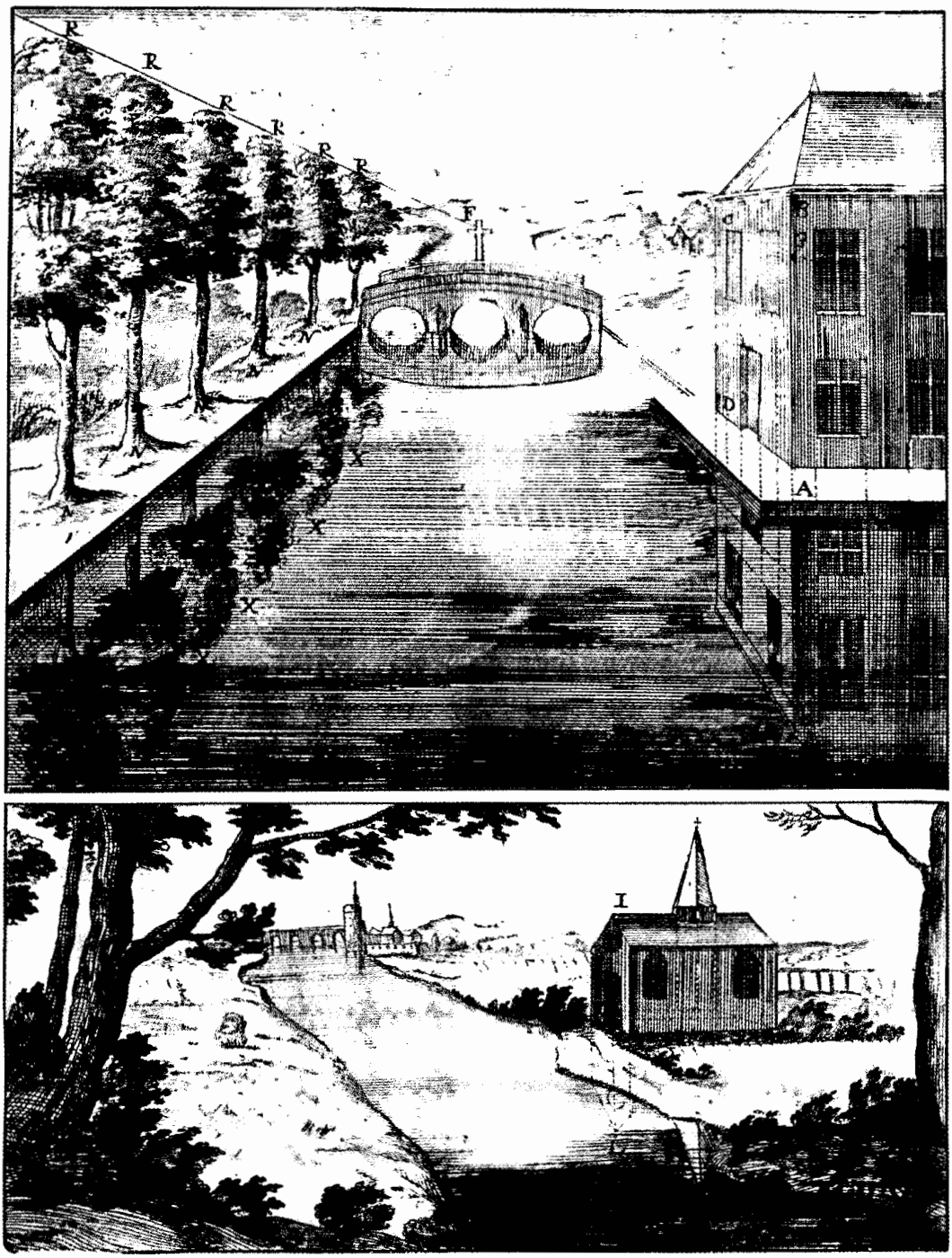
periodo contemporáneo o los estudios regionales. Para el inicio de este proceso en mucho ayudaron las conexiones con perspectivas analíticas de las ciencias sociales en Europa y Estados Unidos, así como la profesionalización y la institucionalización de la ciencia de la historia en México. ${ }^{24}$

La historiografía de tema político, desde entonces, se concentró en el estudio de las relaciones centro-periferia, es decir, las mediaciones y las relaciones entre el centro político nacional y las dinámicas de los estados o regiones, sobre todo, a partir del estudio de los movimientos sociales, los actores históricos, los caciques, los caudillos, los líderes que, desde el ámbito de las regiones llevaron a cabo un proyecto o programa distinto con respecto al centro nacional. Esta perspectiva de investigación y análisis fụe la impulsora principal del revisionismo en torno a la revolución y a la posrevolución en los setenta y los ochenta. ${ }^{25}$

La intermediación política, los conflictos políticos y electorales, la configuración de las clases políticas, la formación y actuación de los partidos y organizaciones, la utilización política de las masas, la instrumentación de la centralización y la institucionalización y la oposición de las regiones, los conflictos Iglesia-Estado y los problemas de los legislativos estatales con los gobernadores, fueron los principales temas de la historiografía política regionalista en los mencionados decenios. ${ }^{26}$

${ }^{24}$ Matute, "Precursores", 1995, pp. 50 y ss.; Villoro, "Tarea", 1960, p. 339, y González, "Usos", 1983, pp. 8-9.

${ }_{25}$ Véase lo que menciona Medina, "Historia", 1998, pp. 299 y ss.; Loaeza, "México", 1995, pp. 151 y ss.

${ }^{26}$ Sería interminable la lista bibliográfica sobre estas obras, que por lo demás están analizadas por Me-
La preocupación constante por el estudio de las relaciones entre la sociedad y el Estado, sobre todo en el periodo de la posrevolución, representó, indiscutiblemente, el objeto de estudio más socorrido dentro de la historiografía regionalista mexicana, prácticamente desde finales de los sesenta. 27

Dentro de la historiografía regionalista hubo avances considerables que rompieron con las interpretaciones parciales o globales de la historiografía nacional, que también experimentaba cambios sustanciales dentro de sus perspectivas temáticas y analíticas.

La corriente revisionista de la historiografía nacional emergió a partir del libro de John Womack sobre el zapatismo, aparecido en 1965 en Estados Unidos, ${ }^{28}$ que vino a cuestionar la interpretación usual de que la revolución mexicana había sido un hecho nacionalista, popular y epopéyico, lineal y homogéneo. Emergieron entonces los actores y sujetos sociales que habían condicionado que la revolución fuera un conjunto de revoluciones y proyectos, movimientos sociales y programas políticos heterogéneos, bases desde las cuales podría reinterpretarse la historia contemporánea de México. Womack afianzó la visión popular y agrarista de ese proceso histórico, estimulando también la interpretación de la historia regional desde la mirada mediadora del contexto nacional, evidentemente centrada en la actuación de los sujetos históricos, lo que representó una importante novedad. ${ }^{29}$

dina "Historia", 1998, pp. 300 y ss. Algo de esto se emprende también en Serrano, "Historia", pp. 3 y ss.

${ }^{27}$ Matute, "Historia", 1992, p. 71.

${ }^{28}$ Womack, Zapata, 1969.

${ }^{29}$ Falcón, "Regiones", 1990, p. 69. 
Del lado regionalista, en 1968 Luis González y González dio a conocer su libro Pueblo en vilo, microbistoria de San José de Gracia, ${ }^{30}$ donde se planteaba la reivindicación académica de la microhistoria como alternativa para reforzar la historia regional mexicana a partir de la diferenciación, la pluralidad y la heterogeneidad, siempre presentes en la historia nacional a partir de barrios, pueblos, comunidades, municipios, estados y regiones, niveles espaciales que contaban con su propia historia e identidad, cuyos universos eran una totalidad histórica de larga, mediana y corta duración. Las fuentes primarias, la tradición oral y el andamiaje profesional del historiador regionalista daban la pauta para reforzar este tipo de estudios, marginados de la historiografía nacional, desde sus vertientes de la historia patria, la historia de bronce y la historia oficial, pero también desde el punto de vista de la historiografía académica. Era hora de reivindicar la historia regional desde una perspectiva universalista y total, frente a las interpretaciones lineales y homogéneas de la historia global nacional, pero también, evidentemente, para renovar este tipo de historiografía frente a las corrientes tradicionales que se seguían cultivando, atrapadas en la crónica, la narrativa, lo autodidacta y lo político. ${ }^{31}$

Ambas aportaciones historiográficas dieron pie a una bifurcación de la histo-

${ }^{30}$ González, Pueblo, 1968. El prólogo de la obra era muy claro en cuanto a intenciones y objetivos, dicho sea de paso.

${ }^{31}$ Véase del mismo González, Invitación, 1997, pp. 20 y ss. Sobre el significado de la obra de Luis González y González, para la historiografía mexicana, véase Ochoa, Pueblo, 1994, en especial los trabajos de José Lameiras, pp. 27-36, José María Muriá, pp. 49-56, y Carlos Martínez Assad, pp. 75-82. riografía nacional en los setenta, resaltando las corrientes revisionistas centradas en el análisis y estudio de la revolución mexicana y sus secuelas, y las corrientes que privilegiaron los estudios relacionados con la historia municipal, estatal y regional de largo alcance, pero también vinculados al revisionismo en materia de estudios de la revolución mexicana. ${ }^{32}$

La historiografía nacional se vio estimulada por la corriente revisionista, que cuestionó la realidad y el cambio de la revolución y se abocó a desmitificarla para cuestionar al autoritarismo gubernamental priista, la caída del llamado "milagro mexicano" y la identidad unificadora que tenía aplastada la interpretación nacionalista de cariz oficial. Las contradicciones entre la realidad histórica del país, después del movimiento de 1968 no eran ya justificables a partir de la historia de la revolución, y mucho menos convincentes para la historia patria y la historia de bronce, cuyos símbolos y valores caían por su propio peso, sobre todo, a partir de un enfoque académico que recuperaba las fuentes y sintetizaba procesos históricos heterogéneos fuera del campo de la interpretación nacionalista. ${ }^{33}$

${ }^{32}$ El revisionismo se entiende aquí como la continua recurrencia a "revisar" los periodos históricos a la luz de la historiografía nacional, en especial en las regiones, pero también a partir de la revolución mexicana. El revisionismo se expresó a partir del encuentro de carencias y ausencias, pero significados también de ciertas etapas de la historia de México. A la luz del presente se recrean elementos o se llenan huecos historiográficos. Esta concepción está lejana de la visión ortodoxa de la revisión ideológica de las revoluciones. Véase al respecto Knight, "Interpretaciones", 1990, pp. 193 y ss.

33 Zermeño, "Historia", 1990, pp. 28 y ss. 
Con esta perspectiva, la historiografía nacional se renovó a partir de los esfuerzos por la síntesis global, pero también a partir de logros analíticos provenientes de la sociología, la ciencia política, la antropología y la economía. El revisionismo historiográfico permaneció en el decenio de los setenta y continuó en buena parte de los ochenta. Las monografías y las síntesis fueron privilegiadas en este periodo, tanto por historiadores mexicanos como por extranjeros. ${ }^{34}$

Los sintetizadores nacionales y extranjeros, como los denomina Alan Knight, dentro del revisionismo, pulularon, y las especializaciones temáticas y monográficas también, especialmente concentradas en las historias cuantitativas, orales, de las relaciones internacionales, agrarias, laborales, educativas, de los movimientos sociales, de las relaciones Iglesia-Estado, biográficas ligadas a la política, ideológicas. La producción historiográfica fue abundante y relacionada con la revolución mexicana, encontrando causas, evolución y consecuencias, pero igual encontró la manifestación de los "muchos Méxicos", un mosaico complejo, variado, plural y heterogéneo que encontró cabida para desmitificar a la revolución popular, monolítica y lineal que la historia patria, la historia de bronce y la historia oficial habían impulsado desde 1920. De alguna forma se recuperó la interpretación de Frank Tannenbaum elaborada en los treinta sobre la heterogeneidad y multiplicidad del proceso revolucionario, ${ }^{35}$

34 Véase el artículo de Knight, "Interpretaciones", 1990, p. 197; Garciadiego, "Revisionistas", 1990, pp. 219-221.

35 Véase Hale, "Frank", 1997, pp. 127-166. marcado por las identidades, sociedades $y$ realidades locales y regionales. ${ }^{36}$

Aparejada a la corriente revisionista, sin embargo, la corriente regionalista emergió estrechamente vinculada con los trabajos de John Womack y Luis González y González; frente a los sintetizadores, los regionalistas prefirieron ahondar en las diversidades, los fragmentos, las particularidades y los espacios microhistóricos, a partir de la monografía, sin descartar la interpretación vinculada con las relaciones centro-periferia y su cercanía con las causas, desarrollo y secuelas de la revolución, concentrándose en el periodo de 1900 hasta $1940 .^{37}$

El enfoque historiográfico regionalista brindó amplias posibilidades para la historia académica profesional de historiadores o cientistas sociales mexicanos y extranjeros que, por medio de las fuentes primarias y los enfoques teórico-metodológicos, lograron estimular y renovar la historiografía regional, siempre frente a la historiografía nacional, sin una postura oficial o patriotera muy común en los estados de la república. ${ }^{38}$

Los regionalistas abrieron una brecha impresionante en los estudios históricos, privilegiando la revolución y la posrevolución, pero también al siglo XIX y el porfiriato, sobre todo, en el decenio de los ochenta, cuando esta corriente de interpretación histórica alcanzó su madurez e

${ }^{36}$ Véanse las apreciaciones de Knight, Bailey, Benjamin, Florescano y Martínez Assad, citadas anteriormente.

${ }^{37}$ Véase al respecto el análisis emprendido por la historiografía extranjera, principalmente estadunidense: Carr, "Recent", 1980, pp. 3-14; Benjamin, "Revolución", 1996, pp. 427 y ss.

${ }^{38} \mathrm{Al}$ respecto véase Gilderhus, "Many", 1987, pp. 255-266, y Hall, "Mexican", 1987, pp. 413-420. 
impulsó un boom dentro de la historiografía de México. Este parteaguas comenzó en los setenta, con los trabajos de Héctor Aguilar Camín, Enrique Krauze, Romana Falcón, Carlos Martínez Assad, Paul Friedrich, Heather Fowler Salamini, Francisco Paoli y Enrique Montalvo, concentrados en distintos aspectos relacionados con la revolución. ${ }^{39}$

Dos historiografías renovadas surgieron en los decenios de los setenta y los ochenta. La nacional, concentrada en la síntesis y la interpretación multidisciplinaria, o en los temas de las relaciones internacionales, la estructura agraria o la cuestión laboral. En ella fueron importantes los trabajos de Jean Meyer, John M. Hart, Ramón Ruiz, Hans Werner Tobler, John Tutino, Lorenzo Meyer, Pablo González Casanova, Eugenia Meyer, Friedrich Katz, Enrique Semo, Adolfo Gilly, Arnaldo Córdova, Alan Knight y François-Xavier Guerra, los cuales retomaron los enfoques concentrados en la interpretación marxista y popular, el de Tannenbaum sobre la multirrevolución regionalista, el de la explicación ideológica, el del movimiento de las elites políticas, el del mundo agrario, el esquema laboral, y el que considera a la nación heterogénea y multirrevolucionaria en movimientos sociales y actores. ${ }^{40}$

Por su parte, la historiografía regional se presentó con un mosaico temático concentrado en la revisión de importantes momentos y fenómenos revolucionarios, más aún porfirianos o posrevolucionarios, mediados o marcados por las relaciones

\footnotetext{
${ }^{39}$ Véase con el balance emprendido por Florescano, Nuevo, 1991, pp. 72 y ss.

${ }^{40}$ Serrano, "Historiografía", 2000, pp. 5-6. Véase con las apreciaciones al respecto de Knight, "Interpretaciones", 1990, p. 198.
}

con el centro nacional, los cuales se diferenciaron por estados como San Luis Potosí, Sonora, Veracruz, Tabasco, Yucatán, Michoacán, Jalisco, Oaxaca, Estado de México, Sinaloa, Guerrero, Hidalgo, Chihuahua o Aguascalientes y también por regiones. ${ }^{41}$

Las relaciones centro-periferia o la intermediación política fueron recurrentes y conformadores de la historiografía política enfocada a las regiones y estados de la república, marginando los temas o periodos de la historia contemporánea después de 1940, materia de la cual los estudiosos de la ciencia política, la antropología política o la sociología política se apoderaron, privilegiando procesos electorales, actuación de partidos políticos, políticas públicas, conflictos políticos y relaciones institucionales o burocráticas con el centro nacional. ${ }^{42}$

Hacia finales de los ochenta se emprendieron esfuerzos colectivos en la revisión de problemas contemporáneos en cada estado de la república. Desde la UNAM, Pablo González Casanova encabezó a un equipo de historiadores, politólogos, sociólogos, economistas o antropólogos, para conformar la Colección Biblioteca de las Entidades Federativas, producto de un seminario fundado en cada estado de la república desde 1.985 , con financiamiento de la Universidad de las Naciones Unidas, cuyo objetivo era analizar los aspectos sociales, económicos, políticos y culturales, relacionados con los problemas de la hegemonía, la democracia y el desarrollo económico social en la historia contemporánea de México. Es-

\footnotetext{
${ }^{41}$ Martínez Assad, Sentimientos, 2001, pp. 122-123.

${ }^{42}$ Véase las consideraciones de Medina, "Historia", 1998 , p. 304.
} 
tas revisiones, muy analíticas y generales, marcadas por la teoría, se concentraron en problemas contemporáneos, cuyo germen, en algunos casos, tenía causales en la posrevolución, sin mucho sustento documental, pero con un esfuerzo analítico destacado, sin incorporar un análisis histórico sistemático o sustentado en fuentes de primera mano. 43

Dentro de la historiografía regionalista, sin embargo, hubo intentos por el estudio y el análisis de las dinámicas políticas en los estados de Oaxaca, Tlaxcala, Veracruz, Yucatán, Sonora, Jalisco, Michoacán, Distrito Federal, Puebla, que dedicaron varios temas sobre el avilacamachismo, el alemanismo o el decenio de los cincuenta, igualmente, sobre las relaciones centro-periferia, los procesos electorales, la actuación de gobernadores o líderes políticos, los conflictos políticos o la puesta en marcha de políticas públicas federales. Esta producción historiográfica fue producto de tesis de posgrado, en su gran mayoría, y en libros de circulación nacional que abrieron brecha para el estudio de periodos posteriores a $1940 .{ }^{44}$

Durante el decenio de los noventa, sin embargo, los historiadores ampliaron sus objetos de estudio dentro del análisis político, pero también a partir de temáticas y periodos. Existió una preocupación constante por el estudio de los procesos electorales estatales, así como también por la relación entre el centro político presidencial y los gobernadores de los estados. ${ }^{45}$ libros.

${ }^{43}$ Así se establecía en las contraportadas de los

${ }^{44}$ Ver Medina, "Historia", 1998, pp. 301 y ss.

45 Ejemplos de esto fueron Martínez, Estadistas, 1988; o Hernández, Formación, 1991; aunque hubo otra gran cantidad de aportaciones en este sentido.
Dentro de la historiografía nacional resaltaron los estudios de Enrique Krauze y su equipo. Las Biografías del Poder, publicadas por el Fondo de Cultura Económica desde 1987, representaron una aportación destacada en el renacimiento de la biografía política, desde la perspectiva académica, pero con la tendencia de la narrativa y la gran difusión, concentradas en las vidas de los presidentes, de Porfirio Díaz a Lázaro Cárdenas, contemplando a líderes como Francisco Villa y Emiliano Zapata. ${ }^{46}$

Después vino un libro galardonado en España con el Premio Comillas, Siglo de caudillos, ${ }^{47}$ dedicado al panteón biográfico y político mexicano del siglo XIX, donde se hace, adicionalmente, un cuestionamiento a la historia de bronce tradicional $\mathrm{y}$ oficial, para valorar el estatus de héroes y villanos de importantes personajes decimonónicos, mostrando a los hombres de "carne y hueso" y reivindicándolos dentro de la historiografía nacional. Enseguida, el proyecto biográfico de Krauze continuó con La presidencia imperial, ${ }^{48}$ de 1997 , importante aportación para la historiografía nacional contemporánea, concentrada en

${ }^{46}$ Este proyecto tuvo la intención de recuperar a los presidentes y líderes de la revolución y posrevolución con ocho libros, uno por cada uno. El resurgimiento de la biografía histórica del panteón mexicano, con bases metodológicas en Carlyle, renovó a esta rama de la historiografía en México. Krauze la había cultivado desde 1971 .

47 Con este libro, Krauze asentaba el resurgimiento de Carlyle dentro de la historia de bronce concentrada en la biografía política, tan importante para la historiografía nacional, pero ahora con un punto de vista académico y divulgador.

${ }^{48}$ A través de la actuación de los presidentes, Krauze intentaba hacer el análisis del sistema político mexicano en la historia del siglo Xx. 


\section{SECUENCIA}
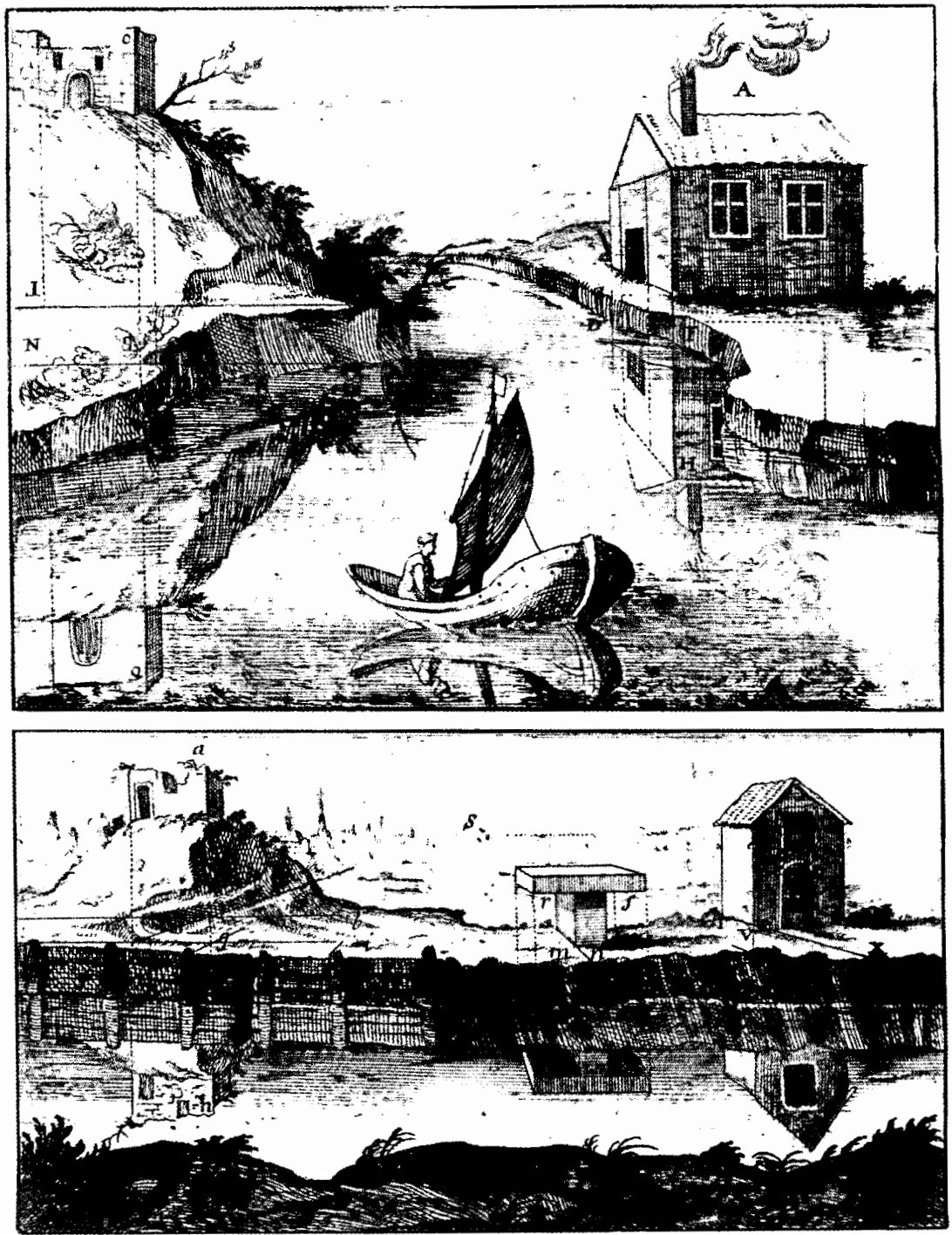
la vida y acciones de los presidentes de 1940 a 1997, es decir, de Manuel Ávila Camacho a Ernesto Zedillo. Krauze, preocupado por las circunstancias políticas nacionales, además publicó varios libros sobre la cuestión nacional en el pasado inmediato, brindando su opinión ideológica y política en función de la perspectiva de la historia. ${ }^{49}$

Las historias generales o de síntesis de los estados, apoyadas por Universidades o gobiernos estatales, fueron muy populares y extendidas en el decenio de los noventa, resaltando el estudio descriptivo de la esfera política posterior a 1940 o de la acción pública de los gobernadores en su relación con la federación, tales fueron los casos de los estados de Sonora, Michoacán, Colima, Jalisco, Zacatecas, Tlaxcala, Guerrero, entre otros más, que revisaron la actuación política de los gobernadores, las elites, las relaciones entre los legislativos y ejecutivos, la política pública y los procesos electorales, como líneas principales de la historia política estatal, privilegiando también las relaciones con el centro político nacional, fundamentalmente, con los presidentes y la puesta en marcha de sus políticas públicas. ${ }^{50}$

La revisión de procesos electorales federales y estatales entre las décadas de los setenta, los ochenta y los noventa, fue un tema recurrente del análisis político y la historiografía del pasado inmediato. La emergencia de conflictos políticos o la presencia de grupos o corrientes políticas de derecha o de izquierda, la presencia de movimientos y líderes civiles, fueron te-

49 Como ejemplos, véase Krauze, Caras, 1983 ; Tiempo, 1996, Tarea, 2000.

${ }^{50}$ Serrano, "Historia", p. 15. mas fundamentales de esta producción historiográfica, fundamental para entender el sistema político mexicano, en proceso de descomposición por la dictadura del PRI. ${ }^{51}$

A pesar de los avances en la historiografía de tema político, las ausencias y carencias temáticas y de periodos de la historia contemporánea de México, enfocados a las regiones, siguen siendo amplias y con destacadas perspectivas para el futuro. El análisis de los sistemas políticos estatales es un tema general que ofrece importantes perspectivas de estudio y análisis, por parte de historiadores y politólogos. ${ }^{52}$ Historia y análisis político siguen siendo dos enfoques que permiten la interdisciplinariedad y la aportación historiográfica que ha abierto el actual milenio. Las perspectivas son halagüeñas en este sentido. La apertura democrática del 2 de julio de 2000 , sin duda, merecerá el estudio y análisis de importantes procesos políticos locales, regionales, estatales y nacionales, sobre todo del periodo de 1940 a la actualidad, un objeto de estudio amplio y polifacético que los historiadores tendremos que abordar, indiscutiblemente.

${ }^{51}$ Loaeza, "Historias", 2001, pp. 47-49. El mismo proyecto de Pablo González Casanova continuó brindando frutos en este sentido, además de aportaciones de estudiosos sobre los procesos electorales y los líderes políticos, cuya historiografía es vasta y proveniente de los politólogos.

${ }^{52}$ González, "Historia", 2002, pp. 71-77. 


\section{BIBLIOGRAFÍA}

-Bailey, David, "Revisionism and the Recent Historiography of the Mexican Revolution", Hispanic American Historical Review, vol. 58, núm. 1, 1978, pp. 62-79.

-Benjamin, Thomas, "La revolución es regionalizada. Los diversos Méxicos en la historiografía revolucionaria" en Thomas Benjamin y Mark Wasserman (coords.), Historia regional de la revolución mexicana. La provincia entre 19101929, CNCA, México, 1996.

"The Leviatan on the Zocalo: Recent a Historiography of the Posrevolutionary Mexican State", Latin American Research Review, vol. 20, núm. 3, septiembre de 1985, pp. 195217.

-Carr, Barry, "Recent Regional Studies of the Mexican Revolution", Latin American Research Review, vol. 1, núm. 15, 1980, pp. 3-14.

-Cockroft, James Donald, Precursores intelectuales de la revolución mexicana (1900-1913), trad. de María Eunice Barrales, SEP, México, 1985.

-Córdova, Arnaldo et al., "Vieja revolución ¿nueva historiografía?", Universidad de México, Revista de la Universidad Nacional Autónoma de México, vol. xiIv, núm. 466, noviembre de 1989, México, pp. 18-25.

-Córdova, Arnaldo, La ideología de la revolución mexicana: la formación del nuevo régimen, Era, México, 1973.

- La política de masas del cardenismo, Era, México, 1974.

-Deutscher, Isaac, Trotsky. El profeta desarmado, Era, México, 1968.

-Falcón, Romana, "Las regiones en la revolución. Un itinerario historiográfico" en Carlos Martínez Assad (coord.), Balance y perspectiva de los estudios regionales en México, UNAM, México, 1990, pp. 61-89.

-Florescano, Enrique, "La influencia del Estado en la historiografía mexicana", Siempre, Su- plemento La Cultura en México, núm. 759, 31 de agosto de 1976, México, Pp. IV-XI.

na, México, 1991.

-Furet, François, Pensar la revolución francesa, Petrel, Madrid, 1980.

-Garciadiego, Javier, "Revisionistas al paredón" en Memorias del simposio de historiografía mexicanista, pp. 219-221.

-Garrido Asperó, María José, "Por caminos desacostumbrados: el proceso ideológico de la revolución de independencia", artículo inédito.

-Gilderhus, Mark T., "Many Mexico's: Tradition and Innovation in the Recent Historiography", Latin American Research Review, vol. 2, núm. 22, 1987, pp. 255-266.

-González y González, Luis, Pueblo en vilo, microhistoria de San José de Gracia, El Colegio de México, México, 1968.

- "Suave patria, revela ya tu verdadera historia", Universidad de México, Revista de la Universidad Nacional Autónoma de México, nueva época, núm. 24, abril 1983, México, pp. 17-22.

, "Usos y abusos de la historiografía mexicana actual", en Panorama actual de la historiografía mexicana, Instituto Mora, México, 1983.

—, "75 años de investigación histórica en México" en México, setenta y cinco años de Revolución, INEHRM/FCE, México, 1988, t. IV, pp. 649-704.

- Invitación a la microbistoria, Clío/El Colegio Nacional, México, 1997.

"De la historia tradicional a la historia académica", Metapolítica, vol. 6, núm. 22, marzo-abril 2002, México, pp. 71-77.

-Hale, Charles A., "Frank Tannenbaum y la revolución mexicana", Secuencia, nueva época, núm. 39, septiembre-diciembre de 1997, México, pp. 1.27-166.

-Hall, Linda B., "The Mexican Revolution and Its Aftermath: Perspectives from Regional 
Perspectives", Mexican Studies/Estudios Mexicanos, vol. 2, núm. 3, verano de 1987, pp. 413-420.

-Hernández, Rogelio, La formación de un político mexicano. El caso de Carlos A. Madrazo, ColmeX, México, 1991.

-Knight, Alan, "Interpretaciones recientes de la revolución mexicana" en Memorias del simposio de bistoriografía mexicana, pp. 193-210.

-Krauze, Enrique, Caras de la bistoria, Joaquín Mortiz, México, 1983. lona, 1994. 1996.

- Tiempo contado, Océano, México, Barcelona, 1997.

$$
\text { La presidencia imperial, Tusquets, }
$$

, Tarea política. Ensayos políticos, 1980-2000, Tusquets, México, 2000.

-Loaeza, Soledad, "El cambio político en México en el siglo Xx. Analogías y orígenes de la discontinuidad de 1988" en Memorias del simposio de bistoriografía mexicanista, pp. 529-539.

_- "México: el cambio político en el siglo xx" en Marco Palacios (comp.), Siete ensayos de bistoriografía, España, Argentina, México, Universidad Nacional de Colombia, Bogotá, 1995.

$$
\text { - "De historias oficiales y leyendas }
$$
negras", Nexos, núm. 285, septiembre de 2001, México, pp. 47-49.

-Martínez Assad, Carlos (coord.), Estadistas, caudillos y caciques, Instituto de Investigaciones Sociales-Unam, México, 1988.

- Los sentimientos de la región, del viejo centralismo a la nueva pluralidad, INEHRM/Océano, México, 2001.

-Matute, Álvaro, "Los actores sociales de la revolución en 20 años de historiografía, 19681988", Universidad de México, Revista de la Universidad Nacional Autónoma de México, vol. XIIV, núm. 466, noviembre de 1989, México, pp. 10-17.
_- "Historia política" en Horacio Crespo et al., El bistoriador frente a la bistoria, corrientes bistoriográficas actuales, Instituto de Investigaciones Históricas-UNAM, México, 1992, pp. 69-78.

, "Precursores de la historiografía regional" en Universidad de México, Revista de la Universidad Nacional Autónoma de México, núm. 538, noviembre de 1995, México, pp. 50-53. - "El 68 y la historia", Estudios bistoriográficos, CIDHEM, Cuernavaca, 1997, pp. 87-95.

-Medina Peña, Luis, "Historia contemporánea de México. ¿Tema de historiadores?" en Gisela von Wobeser (coord.), Cincuenta años de investigación bistórica en México, Instituto de Investigaciones Históricas-UNAM/Universidad de Guanajuato, México, 1998, pp. 293-311.

-Memorias del simposio de historiografía mexicanista, Comité Mexicano de Ciencias Históricas/Gobierno del Estado de Morelos/Instituto de Investigaciones Históricas-UNAM, México, 1990.

-Ochoa Serrano, Álvaro (ed.), Pueblo en vilo, la fuerza de la costumbre, bomenaje a Luis González y González, El Colegio de Jalisco/Colmex/El Colegio de Michoacán, México, 1994.

-Ortega y Gasset, José, "Ideas y creencias" en Obras, Espasa-Calpe, Madrid, 1943, t. Il, pp. 1657-1700.

— El tema de nuestro tiempo, EspasaCalpe, Buenos Aires, 1938 (Colección Austral).

-Pérez Montfort, Ricardo, "Entre la historia patria y la búsqueda histórica de 'lo mexicano". Historiografía mexicana, 1938-1952" en Gisela von Wobeser (coord.), Cincuenta años de inwestigación bistórica en México, Instituto de Investigaciones Históricas-UNAM/Universidad de Guanajuato, México, 1998.

-Salmerón Sanginés, Pedro, "Pensar el villismo", Estudios de Historia Moderna y Contemporánea de México, vol. 20, 2000, México, pp. 101-128. 
-Sartori, Giovanni, Partidos y sistemas de partidos, Alianza, Madrid, 2000.

-Serrano Álvarez, Pablo, "Historia regional contra historia nacional en el siglo XX. Encuentros, desencuentros y situación actual", artículo inédito.

"Historiografía local y regional sobre la revolución mexicana. Estado actual y perspectivas", Sólo Historia, núm. 10, octubre-diciembre de 2000, México, pp. 4-8.

, "La historiografía regional de México. Balance, situación y perspectivas. A manera de introducción" en Pablo Serrano (coord.), Pasado, presente y futuro de la bistoriografía regional de México, Instituto de Investigaciones Históricas-UNAM, México, 1998, pp. 16-26.

-Torres Sánchez, Rafael, Revolución y vida cotidiana en Guadalajara, 1914-1934, Universidad Autónoma de Sinaloa, Culiacán, 2001.

-Vanderwood, Paul J., "Explicando la revolución mexicana", Secuencia. Revista Americana de Ciencias Sociales, vol. 13, enero-abril de 1989, México, pp. 5-22.
- Villoro, Luis, "Sobre el concepto de revolución", Teoría. Revista de Filosofía, año 1, núm. 1, julio de 1993, México, pp. 69-86.

___ "La tarea del historiador desde la perspectiva mexicana", Historia Mexicana, vol. XI, núm. 3, enero-marzo de 1960, México, pp. 327-339.

-Wallerstein, Immanuel, "1968: revolución en el sistema-mundo. Tesis e interrogantes", Estudios Sociológicos de El Colegio de México, vol. viI, núm. 20, mayo-agosto de 1998, México, pp. 229-249.

- Utopística o las opciones bistóricas del siglo XXI, FCE/UNAM, México, 1998.

-Womack, John, Zapata y la revolución mexicana, Siglo XXI, México, 1969.

-Zermeño, Guillermo, "La historia. ¿Una ciencia en crisis? Teoría e historia en México, 1968-1988: una primera aproximación" en Memorias del simposio de historiografía mexicanista, pp. 26-32. 